\title{
Maggot debridement therapy: the current perspectives
}

This article was published in the following Dove Press journal:

Chronic Wound Care Management and Research

3 October 2017

Number of times this article has been viewed

\author{
Gurudutt Naik \\ Keith G Harding \\ Welsh Wound Innovation Centre, \\ Cardiff University, Cardiff, UK
}

Correspondence: Gurudutt Naik Welsh Wound Innovation Centre, Cardiff University, Rhodfa Marics, Ynysmaerd, Pontyclun, Rhondda Cynon Taf, CF72 $8 \mathrm{UX}$, Wales, UK

Tel +4429 I443443870

Email NaikG@cf.ac.uk

\begin{abstract}
Chronic wounds remain a challenge to most healthcare systems worldwide despite the technological advances we have seen to date. Many chronic non-healing wounds require alternative approaches, in addition to standard conventional therapies. Maggot debridement therapy (MDT) or the use of maggots to treat wounds is one such therapy that has been in use for centuries. We conducted a review of articles published in PubMed, NICE evidence documents, and linked literature with the aim of providing a brief perspective on the evolution of MDT, and the context in which maggot therapy is currently used along with evidence behind such methods. Keywords: wound healing, maggot debridement therapy, debridement, Lucilia sericata, chronic disease, larva
\end{abstract}

\section{Introduction}

The burden of wounds is probably as old as mankind itself. Even with vast advances in today's healthcare technology, the management of chronic wounds still poses a significant challenge to the medical world. ${ }^{1,2}$ The cost to the National Health Service of caring for patients with a chronic wound is conservatively estimated at $£ 2.3 \mathrm{~b}$ to $£ 3.1 \mathrm{~b}$ per year (at 2005-2006 costs); it is around 3\% of the total estimated expenditure on health $(89.4 \mathrm{~b}) .^{3}$ The total cost of managing patients with wounds, originating in primary care, accounted for nearly $6 \%$ of the total expenditure on the health service in Wales, at an average cost of $£ 1727$ per patient. ${ }^{4} \mathrm{~A}$ high proportion of chronic wounds remain unhealed for long periods, and this may be due to the use of inappropriate or ineffective therapies, as clinical staff are not trained or aware of optimal ways of managing such patients. Many patients with chronic wounds tend to have other underlying conditions making wound healing extremely difficult even where specialized care is provided in order to expedite the process. Many chronic non-healing wounds therefore require targeted approaches rather than the standard conventional therapies.

Maggot debridement therapy (MDT) or the use of maggots to treat wounds is one such therapy that has been in use for centuries. ${ }^{5}$ Larvae of the green bottle fly Lucilia sericata are used in MDT. An important step in assisting chronic non-healing wounds progress through healing is wound bed preparation. This is usually achieved by effective debridement technique to remove devitalized tissue, including slough and eschar. The methods of debriding a wound can be classified as surgical, autolytic, mechanical, enzymatic, or biological. ${ }^{6}$ MDT mainly helps in wound healing by debridement of necrotic tissue by both mechanical and biochemical means. Mechanical debridement is achieved by the "mouth hooks" of the maggots and their rough bodies that 
scratch the necrotic tissue. ${ }^{7}$ They may also secrete a mixture of proteolytic enzymes (trypsin and chymotrypsin-like collagenase) that lyse nonviable tissue, making it easier for the maggots to digest. ${ }^{8}$ This article provides a brief perspective on the evolution of MDT and the context in which maggot therapy is currently being used along with evidence behind such methods.

\section{Methods}

The evidence that forms the basis of this article was identified by searching PubMed, using a two-layer search method using; "Wounds and injuries," "Ulcers," and "Debridement" and "Larva*," "Lucilia sericata" (the widely used binomial nomenclature for the larvae used in MDT), and "Maggot" in titles/abstract. Other literature linked to the articles found on PubMed searches was also used. Major texts in the field were reviewed, including the evidence-based guide to maggot therapy in wounds. Well-conducted systematic reviews were included as part of the evidence base, as well as authoritative articles about the wound healing and suggested best practice guides. We also looked at appraised literature from the National Institute of Clinical Excellence (NICE) evidence search.

\section{Historical use of maggots in wound treatment}

The history of wound care probably dates back to the origin of human species. Wounds can naturally heal by themselves, but humans have noticed several natural remedies that would speed up the process, especially if the wounds were chronic. The use of insects or their products is not new; honey ${ }^{9}$ from bees, cobwebs, ${ }^{10}$ ant-heads ${ }^{11}$ to aid wound closure, and leeches ${ }^{11}$ to help draw excessive wound congestion have all been tried in the past. Maggot therapy is one such ancient method that has stood the test of time and is still being widely used to achieve wound debridement in difficult and chronic wounds. According to Fleischmann et al, "Australian aborigines have used maggots to clean wounds for thousands of years." 12

Many military surgeons noted that soldiers whose wounds became infested with maggots healed better. Ambroise Paré (1509-1590) was a notable barber surgeon who served in the French army. ${ }^{13}$ Pare in the battle of St. Quentin (1557) observed that when maggots were present in suppurating wounds, they healed faster. However, at the time this observation did not result in a new treatment modality. Again, in the 1800s, Napoleon's battlefield surgeon, Dominique Larrey (1766-1842) noted the beneficial effects of maggots on wounds sustained by soldiers during an expedition to Syria. ${ }^{14}$
While Larrey noticed their benefits, he had not deliberately placed blowfly larvae on the wounds. He said they were "greedy only after putrefying substances, and never touch the parts which are endowed with life". ${ }^{14}$ Despite all efforts, Larrey's wounded soldiers were not willing to have the crawling larvae on their wounds and, yet again, did not result in the adoption of this as a new modality of treatment for wounds. Similar observations were made by American Civil War surgeons who ultimately realized that maggots could have beneficial effects. Confederate Surgeon Joseph Jones, for example, reported that "a gangrenous wound which had been thoroughly cleansed by maggots healed more rapidly than if it had been left by itself." ${ }^{15}$ John Forney Zacharias (1837-1901), a surgeon from Maryland during the American civil war was the first to officially document maggot therapy, which he explains as having saved many lives. Later during the First World War, William Baer (1872-1931) noted that maggots assisted in the healing of fracture wounds. ${ }^{16}$ However, while undergoing MDT, some of his patients with fractures died of secondary bacterial infections such as tetanus and gas gangrene. Then after several experiments, Baer successfully devised a method to produce sterilized maggots that would not spread these clostridial infections. Despite the method being expensive, maggots were cultured during that time, and MDT saw one of its peaks in the 1930s. Another contemporary surgeon, Duncan McKeever (1905-1959) credited Baer for the use of maggot therapy in osteomyelitis, and he describes in great detail an inexpensive and easy method of the production of non-sterile maggots and how to apply them in chronic osteomyelitis. ${ }^{17}$ MDT was widely used until after the Second World War, when the discovery of antibiotics and the development of better surgical techniques pushed it to the background. ${ }^{15}$

\section{Renaissance in the new era}

Ronald Sherman, a strong advocate, was the key figure for its revival. In the 1990s, he established a small fly-culturing facility in the Veteran Administration Hospital Medical Centre in Long Beach, California, USA to produce sterile larvae. ${ }^{18} \mathrm{He}$ was one of the first to conduct a prospectivecontrolled study that looked at maggot therapy in treating pressure ulcers in spinal cord-injury patients. ${ }^{19}$ Eight patients received MDT after a baseline assessment of healing under conventional therapy. Maggot therapy led to a more rapid removal of debris than all other non-surgical treatments and had a faster healing rate. No complications were seen. At around the same time, he developed an optimal dressing design which was a two-layered cage-like dressing; the 
bottom layer of which comprised a hydrocolloid pad, applied to the surrounding healthy skin and covered by a fine chiffon or nylon mesh. ${ }^{20}$ The renaissance of MDT in the United Kingdom can be attributed to Dr John Church, an orthopedic surgeon who, along with Dr Stephen Thomas, opened the first Larval Therapy Research Unit at Bridgend, South Wales in 1995. ${ }^{21}$ German and Belgian factories have also distributed fly larvae in Europe since 1998. ${ }^{18}$

In 2000, Wayman et $\mathrm{al}^{22}$ published one of the first conducted randomized-controlled trials (RCTs) on the effectiveness of MDT. They considered a small sample (12 patients) with venous leg ulcers who were treated with MDT or hydrogel. Six wounds in the MDT group had debrided faster (2-3 days) than in the control arm ( $>1$ month). In the same year (2000), another large RCT was conducted by Markevich et al. ${ }^{23,24}$ They included 140 patients with non-healing diabetic neuropathic foot wounds. Compared with conventional therapy, the MDT wounds were successfully debrided twice as often in the 10-day follow-up period $(51.1 \%$ of MDT patients versus $27 \%$ of controls, $p<0.05$ ). Complete healing during the observed time period was twice as frequent as conventional therapy (7.1\% of MDT patients and $2.8 \%$ of controls). Dumville et al in the UK in 2009 conducted the largest RCT. ${ }^{25}$ They included 267 venous or mixed venous arterial ulcers that were treated either with MDT (free living or loose larvae) or hydrogel, and followed up for 12 months in a three-armed trial. They concluded that "Larval therapy did not improve the rate of healing of sloughy or necrotic leg ulcers or reduce bacterial load compared with hydrogel but did significantly reduce the time to debridement and increased ulcer pain." ${ }^{25}$ Paul et al, also in the same year (2009), conducted a case control series of MDT on diabetic foot ulcers. ${ }^{26}$ In this series, they included 29 patients and 30 controls; there was no significant difference in outcomes between the two groups. They concluded that MDT is as effective as conventional debridement in the treatment of diabetic foot ulcers. They suggested that MDT would be a feasible alternative to those at high risk for surgery or for those who refuse surgery. Another retrospective study by Wang et al followed 25 diabetic foot ulcers and 18 pressure ulcers in spinal cord-injury patients treated with either MDT or traditional dressings. ${ }^{27}$ The MDT group had a significantly shorter time to achieve bacterial negativity, healthy granulation, and complete healing. Finally, the most recent RCT was conducted in 2014 at the Wound Healing Research Unit, Cardiff University by Mudge et al. ${ }^{28}$ This study compared the clinical effectiveness of a larval therapy dressing (BioFOAM) with a standard debridement technique (Purilon gel; hydrogel) in terms of time to debridement of venous or mixed arterial/venous leg ulcers. Out of 88 subjects who were included, 64 completed the study. With withdrawn subjects excluded from the analyses, the ulcers that debrided in the larvae arm were $96.9 \%$ compared with only $34.4 \%$ from the hydrogel arm. Subjects in the MDT arm experienced more ulcer-related pain or discomfort than the subjects in the hydrogel arm. The authors, based on the trial, suggested that provision of pain relief, patient education, and treatment concordance are important factors to be considered to achieve effective and efficient MDT.

\section{Other clinical studies}

Cambal et al published their findings of the MDT method in chronic conservative non-treatable leg ulcers in patients in whom conventional therapy failed. ${ }^{29}$ All ulcers were healed or minimized in size at 4-8 weeks of follow-up. Tantawi et al studied 13 diabetic foot ulcers in 10 patients treated with MDT. ${ }^{30}$ Complete debridement was achieved at a mean of 1.9 weeks, and $85 \%$ of the ulcers healed within a mean of 7.3 weeks. The bacterial load of all ulcers reduced sharply after the first MDT cycle which probably contributed to healing. Marineau et al studied complex diabetic foot wounds, studying a 23-person cohort that included 11 cases of osteomyelitis, 13 patients with poorly controlled diabetes, and five patients with end-stage renal failure on chronic hemodialysis. ${ }^{31}$ In 17 of 23 patients with multiple comorbidities, the treatment of their complex diabetic wounds by MDT resulted in improvement or cure. Gilead et al conducted a retrospective study of patients treated with MDT in their facility. ${ }^{32}$ Out of 723 ambulatory and hospitalized patients treated with MDT, 90.5\% had leg ulcers and $48 \%$ had diabetic foot ulcers. Complete debridement was achieved in $82.1 \%$ of cases, partial debridement in $16.8 \%$, and treatment was ineffective in $1.1 \%$. Increased pain with MDT was seen in $38 \%$ of the treated patients.

There has been a rising trend in the use of MDT after the 1990s. The contexts in which it was used are reflected in the published case reports during the time. It is interesting to note that there were only two case reports within our searches between 1975 and 1990, and 22 case reports were found after 1990. The revival of MDT around the time coincides with the rise of antibiotic resistance, ${ }^{33,34}$ which rendered one of the main modalities of wound treatment ineffective. This is probably why the use of MDT began to rise, but in most cases as the last resort when other modalities failed. MDT was used for a range of wounds ranging from the common venous and diabetic ulcers to more complex and rare forms of chronic wounds. Table 1 presents an overview of the context in which MDT has been used. 


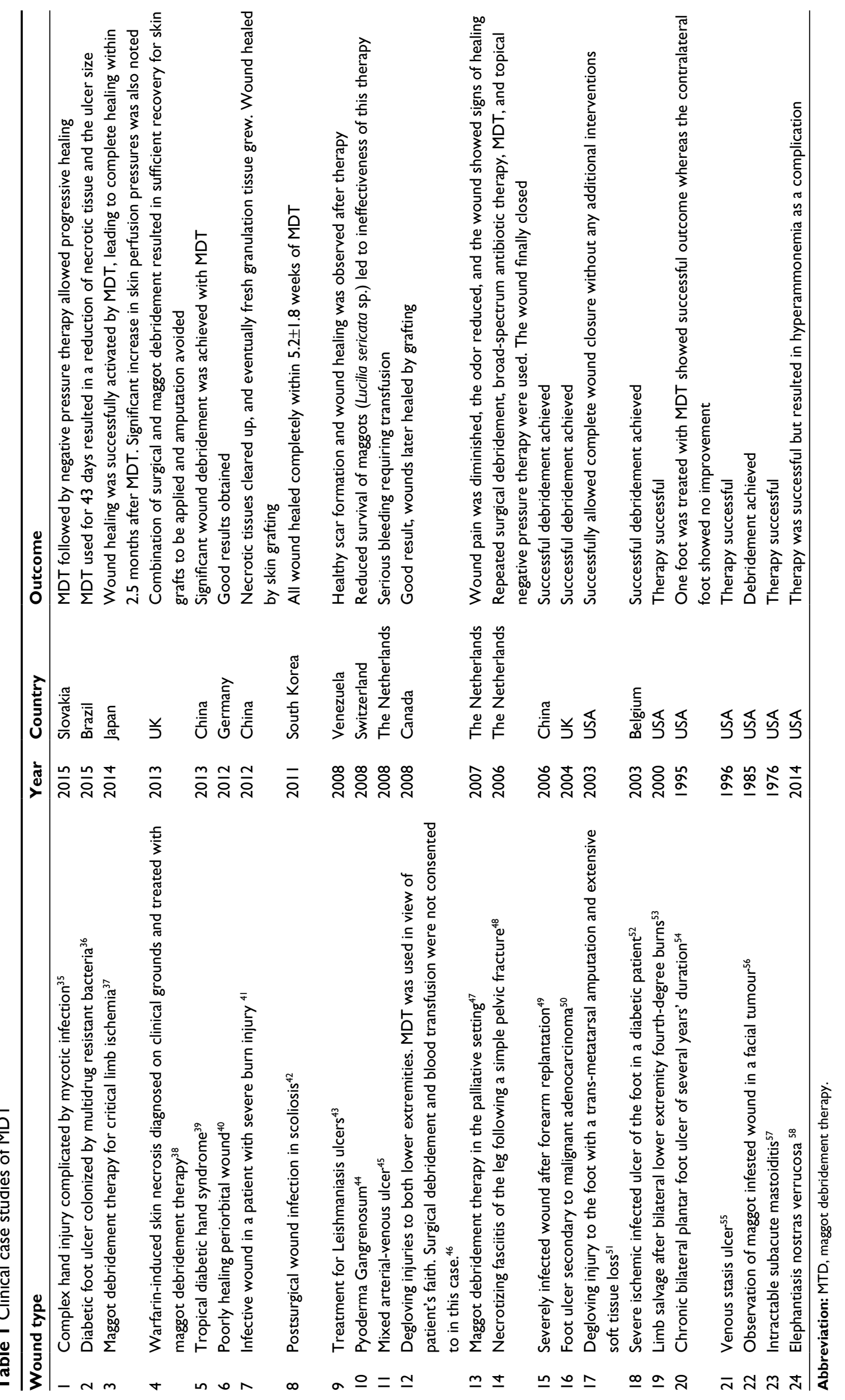


MDT has been used in traumatic, surgical, arterial, venous, and malignant wounds (Table 1). Maggots have also been used in other wounds caused by infections, infestations, drugs, and wounds related to autoimmune conditions. We have identified 24 different clinical situations where MDT has been tried. MDT was successful in 22 out of 24 clinical scenarios. MDT did not help to achieve good results in a case of Pyoderma Gangrenosum where the poor survival of the maggots rendered the therapy ineffective, and in another case of mixed arterial and venous ulcer where bleeding complication was seen. However, the evidence from these case reports can only be considered as anecdotal.

\section{Meta-analyses of MDT studies}

A systematic review by Zarchi and Jemec compiled three RCTs and five non-randomized studies, focusing on the debriding potential of MDT. ${ }^{59}$ They noted that the design of the studies was suboptimal, with differences in the use of other therapies, such as compression, that may influence both debridement and healing process between the compared groups, as well as short follow-up times. They concluded that poor quality of the data used for evaluating the efficacy of MDT called for more and better designed clinical trials. Wilasrusmee et al found MDT helpful in the treatment of chronic ulcers with a $20 \%$ greater chance of wound healing as compared to conventional therapies. ${ }^{60}$ Tian et al (2013) reviewed the efficacy of MDT compared with standard of care for diabetic foot ulcers. ${ }^{61}$ Four studies (356 participants) were meta-analyzed with the conclusion that the evidence for MDT was too weak to routinely recommend it for treatment. Larger studies and sample sizes to assess the efficacy and safety of MDT in the treatment of diabetic foot ulcers were recommended. The recent systematic review by Sun et al (2014) looked at the use of MDT in the treatment of chronically infected wounds. ${ }^{62}$ In these meta-analyzed data, the pooled relative risk was 1.80 (95\% [CI 1.24-2.60]). Subgroup analysis revealed that the combined relative risks were 1.79 (95\% [CI 0.95-3.38]) for patients with diabetic foot ulcers, and 1.70 (95\% [CI 1.28-2.27]) for patients with other types of ulcers. The time to healing of the ulcer was significantly shorter among patients treated with MDT.

\section{Current use of MDT}

Currently, MDT is used mostly when other conventional therapies fail or when non-surgical debridement of the wound is being considered. NICE (UK) suggests considering MDT in chronic pressure ulcers if debridement is needed, but sharp debridement is contraindicated, or if there is associated vascular insufficiency. The Health Service Executive (Republic of Ireland) in their evidence based wound management guidance suggest that in general, removal of all necrotic or devitalized tissue by various methods including MDT leads to a more normal wound-healing process. Maggots received marketing clearance as "medical devices" by the US Food and Drug Administration in January 2004, making them the first live organism marketed in the United States for medical purposes and treatment is currently reimbursable by Medicare. ${ }^{63}$ The Welsh guidelines recommend that an overall clinical decision has to be made when rapid debridement of devitalized tissue is required to achieve wound healing and then an assessment for suitability of the wound before MDT is commenced. ${ }^{64}$

Currently, there are two methods of larval application. The first method is using larvae sealed within a dressing called biobag. They come in varying sizes to match different wound sizes. The larvae remain sealed inside the biobag throughout the treatment period. The other method is to use free-range larvae applied directly on the wound. Biobags can be left in place up to 4 days and free-range larvae are also left in the wound for up to 4 days per application. The number of applications required for complete wound debridement depends on the type of wound and ranges from one to several per treatment session.

\section{Indications and cautions for use}

The most important part of managing a wound is addressing the underlying condition that causes it. MDT can play an adjunct role to wound care. MDT can be used for any type of chronic wounds that have moist slough or necrotic tissue on its floor where urgent surgical debridement (eg, necrotizing fasciitis) is not indicated, possible or refused by the patient. MDT should be used cautiously under close supervision near exposed blood vessels, organs, or wounds body cavities. ${ }^{18,64}$ Bleeding complications have been encountered with previous use of MDT, and close observation of the therapy is required when used in patients with bleeding tendencies, for example, Warfarin induced coagulopathy. ${ }^{45,65}$

\section{Back to the future}

There is a rise in the number of people living with long-term conditions; one of the main reasons why we will see an increase in prevalence of chronic and complicated wounds that are resistant to conventional therapies. The evidence for MDT is encouraging, and we will continue to see a rising trend in its use. Currently, the literature that can provide level 1 evidence is, however, sparse. Most studies so far look 
at proximal short-term outcomes that present a short-sighted view of measuring success of MDT. RCTs of MDT that can capture both proximal and distal outcomes need longer term of follow-up and are expensive and challenging to design. There is a need for more such trials to be conducted in the future that ultimately provide better levels of evidence. Another method to capture more distal outcomes would involve observational studies of large patient cohorts or databases such as Clinical Practice Research Datalink ${ }^{66}$ and Health Wise Wales. ${ }^{67}$ This method can also be a good way of sharing clinical and patient experiences.

There has been a renewed interest in MDT and its role as a form of antimicrobial treatment for infected wounds. With the emergence of antimicrobial resistance, we are again likely to see its increased use in drug-resistant wound infections. Systematic reviews evaluating MDT have highlighted its successful role in treatment of Gram-positive and Gramnegative bacterial strains, including Staphylococcus aureus, Pseudomonas aeruginosa, Methicillin-resistant Staphylococcus aureus, and other drug-resistant pathogens. ${ }^{62,68}$ However, no direct anti-microbial effect of MDT was observed in an in vitro study by Cazander et al, ${ }^{69}$ but other clinical studies have confirmed a decrease in bacterial load following its use. ${ }^{68}$ The main mechanism of antimicrobial activity has been thought to be by the destruction of bacteria in the hind gut of the larvae. ${ }^{70}$ Other mechanisms include excretion of waste products like ammonia by the larvae, and secretion of other bactericides that may be responsible for combating bacterial pathogens. ${ }^{71}$ Evans et al have shown that the larvae of medicinal maggots also have antifungal activity. ${ }^{72}$ More research is needed to demonstrate the indirect antibacterial activity observed in clinical studies, such as the possible presence of the immuno-modulatory effect of MDT.

Another field for future research is the potential of MDT to promote wound healing by stimulating tissue regeneration. High levels of gamma-interferons and interleukins have been shown in maggot excretions. ${ }^{70,71}$ Inappropriate complement activation has been thought to cause tissue destruction, and complement reducing substrate has been identified by Cazander et al in maggot secretions. ${ }^{73}$ This substance could lead to a novel treatment option subject to its detailed identification and reproduction, possibly by recombinant technology. Human growth factors have also been shown to promote wound healing. Further research is underway, where genetic engineering techniques have been used to produce transgenic larvae that can secrete human growth factors such as the human platelet derived growth factor (PDGF-BB). ${ }^{74}$ "Will this be the first step in developing a novel and cost-effective technique of delivering a variety of growth factors and antimicrobial peptides into the wound environment?" is a question that only time can answer.

\section{Conclusion}

Management of chronic wounds still poses a huge challenge, and many chronic wounds require other unconventional therapies in order to achieve healing. MDT is one such alternative therapy that has been used for centuries for wound debridement, and now has re-emerged as an effective option for many wound types. Almost all literature published so far is in support of the use of MDT, however, level 1 evidence is sparse, and more work is needed to further establish the evidence base. Recent research into the cellular mechanisms of action of MDT and genetic engineering techniques may result in novel and innovative therapies in the future that have the potential to revolutionize wound healing.

\section{Disclosure}

The authors report no conflicts of interest in this work.

\section{References}

1. Harding KG, Morris HL, Patel GK. Healing chronic wounds. BMJ. 2002;324:160-163.

2. Harding K. Innovation and wound healing. JWound Care. 2015;24:7-13.

3. Posnett J, Franks PJ. The burden of chronic wounds in the UK. Nurs Times. 2008;104:44-45.

4. Phillips CJ, Humphreys I, Fletcher J, Harding K, Chamberlain G, Macey S. Estimating the costs associated with the management of patients with chronic wounds using linked routine data. Int Wound J. 2016;13:1193-1197.

5. Pritchard DI, Nigam Y. Maximising the secondary beneficial effects of larval debridement therapy. JWound Care. 2013;22:610-611,614-616.

6. Sibbald RG, Goodman L, Woo KY, et al. Special considerations in wound bed preparation 2011: an update(c). Adv Skin Wound Care. 2011;24: 415-436; quiz 437-438.

7. Gottrup F, Jorgensen B. Maggot debridement: an alternative method for debridement. Eplasty. 2011;11:e33.

8. Blake FA, Abromeit N, Bubenheim M, Li L, Schmelzle R. The biosurgical wound debridement: experimental investigation of efficiency and practicability. Wound Repair Regen. 2007;15:756-761.

9. Fonder MA, Lazarus GS, Cowan DA, Aronson-Cook B, Kohli AR, Mamelak AJ. Treating the chronic wound: A practical approach to the care of nonhealing wounds and wound care dressings. $J$ Am Acad Dermatol. 2008;58:185-206.

10. The University of Nottingham. We could make that! A chance meeting leads to creation of antibiotic spider silk. Available from: http://www. nottingham.ac.uk/news/pressreleases/2017/january/chance-meeting-leadsto-creation-of-antibiotic-spider-silk.aspx. Accessed September 24, 2017.

11. Saraf S, Parihar RS. Sushruta: the first plastic surgeon in 600 B.C. The Internet Journal of Plastic Surgery. 2006;4:2.

12. Fleischmann W, Grassberger M, Sherman R. Maggot Therapy. A Handbook of Maggot-Assisted Wound Healing. New York: Thieme; 2004.

13. Drucker CB. Ambroise Paré and the birth of the gentle art of surgery. Yale J Biol Med. 2008;81:199-202.

14. Larrey BD. Observations on wounds, and their complications by erysipelas, gangrene and tetanus, etc. [in French]. Translated from French by E.F. Rivinus; 1832. 
15. Hunter S, Langemo D, Thompson P, Hanson D, Anderson J. Maggot therapy for wound management. Adv Skin Wound Care. 2009;22:25-27.

16. Manring MM, Calhoun JH. Biographical sketch: William S. Baer (1872-1931). Clin Orthop Relat Res. 2011;469(4):917-919.

17. McKeever DC. The classic: maggots in treatment of osteomyelitis: a simple inexpensive method. Clin Orthop Relat Res. 2008;466(6):1329-1335.

18. Whitaker IS, Twine C, Whitaker MJ, Welck M, Brown CS, Shandall A. Larval therapy from antiquity to the present day: mechanisms of action, clinical applications and future potential. Postgrad Med J. 2007;83:409-413.

19. Sherman RA, Wyle F, Vulpe M. Maggot therapy for treating pressure ulcers in spinal cord injury patients. J Spinal Cord Med. 1995;18:71-74.

20. Sherman RA. A new dressing design for use with maggot therapy. Plast Reconstr Surg. 1997;100:451-456.

21. Sherman RA, Hall MJ, Thomas S. Medicinal maggots: an ancient remedy for some contemporary afflictions. Annu Rev Entomol. 2000;45:55-81.

22. Wayman J, Nirojogi V, Walker A, Sowinski A, Walker MA. The cost effectiveness of larval therapy in venous ulcers. J Tissue Viability. 2000;10: 91-94.

23. Markevich Y, McLeod-Roberts J, Mousley M, Melloy E. Maggot therapy for diabetic neuropathic foot wounds: a randomized study. 36th Annual Meeting of the European Association for the Study of Diabetes. September; 2000; Jerusalem, Israel.

24. Sherman RA. Maggot therapy takes us back to the future of wound care: new and improved maggot therapy for the 21 st century. J Diabetes $\mathrm{Sci}$ Technol. 2009;3:336-344.

25. Dumville JC, Worthy G, Soares MO, et al. VenuS II: a randomised controlled trial of larval therapy in the management of leg ulcers. Health Technol Assess. 2009;13:1-182; iii-iv.

26. Paul AG, Ahmad NW, Lee HL, et al. Maggot debridement therapy with Lucilia cuprina: a comparison with conventional debridement in diabetic foot ulcers. Int Wound J. 2009;6:39-46.

27. Wang SY, Wang JN, Lv DC, Diao YP, Zhang Z. Clinical research on the bio-debridement effect of maggot therapy for treatment of chronically infected lesions. Orthop Surg. 2010;2:201-206.

28. Mudge E, Price P, Walkley N, Harding KG. A randomized controlled trial of larval therapy for the debridement of leg ulcers: results of a multicenter, randomized, controlled, open, observer blind, parallel group study. Wound Repair Regen. 2014;22:43-51.

29. Cambal M, Labas P, Kozanek M, Takac P, Krumpalova Z. Maggot debridement therapy. Bratisl Lek Listy. 2006;107:442-444.

30. Tantawi TI, GoharYM, Kotb MM, Beshara FM, El-Naggar MM. Clinical and microbiological efficacy of MDT in the treatment of diabetic foot ulcers. J Wound Care. 2007;16:379-383.

31. Marineau ML, Herrington MT, Swenor KM, Eron LJ. Maggot debridement therapy in the treatment of complex diabetic wounds. Hawaii MedJ. 2011;70:121-124

32. Gilead L, Mumcuoglu KY, Ingber A. The use of maggot debridement therapy in the treatment of chronic wounds in hospitalised and ambulatory patients. J Wound Care. 2012;21:78,80,82-85.

33. Lewis R. The rise of antibiotic-resistant infections. FDA Consumer Magazine. September; 1995.

34. Reacher MH, Shah A, Livermore DM et al. Bacteraemia and antibiotic resistance of its pathogens reported in England and Wales between 1990 and 1998: trend analysis. BMJ 2000; 320: 213.

35. Bohac M, Cambal M, Zamborsky R, Takac P, Fedeles J Sr. Maggot therapy in treatment of a complex hand injury complicated by mycotic infection. Bratisl Lek Listy. 2015;116:671-673.

36. Pinheiro MA, Ferraz JB, Junior MA, et al. Use of maggot therapy for treating a diabetic foot ulcer colonized by multidrug resistant bacteria in Brazil. Indian J Med Res. 2015;141:340-342.

37. Maeda TM, Kimura CK, Takahashi KT, Ichimura KI. Increase in skin perfusion pressure after maggot debridement therapy for critical limb ischaemia. Clin Exp Dermatol. 2014;39:911-914.

38. Biscoe AL, Bedlow A. Warfarin-induced skin necrosis diagnosed on clinical grounds and treated with maggot debridement therapy. BMJ Case Rep. 2013; 2013.
39. Jiang KC, Luo N, Chen YC, Wang AP. Use of maggot debridement therapy for tropical diabetic hand syndrome. J Wound Care. 2013;22:244-247.

40. Pitz S, Renieri G, Gericke A. [Poorly healing periorbital wounds Therapeutic use of maggots]. Ophthalmologe. 2012;109:450-453.

41. Wu JC, Lu RR, Huo R, Fu HB. Maggot therapy for repairing serious infective wound in a severely burned patient. Chin J Traumatol. 2012;15: $124-125$.

42. Hwang JH, Modi HN, Suh SW, Hong JY, Yang JH, Park JH. Maggot debridement therapy for postsurgical wound infection in scoliosis: a case series in five patients. Spine (Phila Pa 1976). 2011;36:313-319.

43. Arrivillaga J, Rodriguez J, Oviedo M. [Preliminary evaluation of maggot (Diptera: Calliphoridae) therapy as a potential treatment for leishmaniasis ulcers]. Biomedica. 2008;28:305-310.

44. Renner R, Treudler R, Simon JC. Maggots do not survive in pyoderma gangrenosum. Dermatology. 2008;217:241-243.

45. Steenvoorde P, van Doorn LP. Maggot debridement therapy: serious bleeding can occur: report of a case. JWound Ostomy Continence Nurs. 2008;35:412-414

46. van Veen LJ. Maggot debridement therapy: a case study. JWound Ostomy Continence Nurs. 2008;35:432-436.

47. Steenvoorde P, van Doorn LP, Jacobi CE, Oskam J. Maggot debridement therapy in the palliative setting. Am J Hosp Palliat Care. 2007;24:308-310.

48. Rozeboom AL, Steenvoorde P, Hartgrink HH, Jukema GN. Necrotising fasciitis of the leg following a simple pelvic fracture: case report and literature review. J Wound Care. 2006;15:117-120.

49. Wang J, Wang S, Zhao G, Wang Z, Lineaweaver WC, Zhang F. Treatment of infected wounds with maggot therapy after replantation. J Reconstr Microsurg. 2006;22:277-280.

50. Sealby N. The use of maggot therapy in the treatment of a malignant foot wound. Br J Community Nurs. 2004;9:S16-S19.

51. Husain ZS, Fallat LM. Maggot therapy for wound debridement in a traumatic foot-degloving injury: a case report. J Foot Ankle Surg. $2003 ; 42: 371-376$.

52. Scavee V, Polis X, Schoevaerdts JC. Maggot therapy: many hands make light work. Acta Chir Belg. 2003;103:405-407.

53. Namias N, Varela JE, Varas RP, Quintana O, Ward CG. Biodebridement: a case report of maggot therapy for limb salvage after fourth-degree burns. J Burn Care Rehabil. 2000;21:254-257.

54. Stoddard SR, Sherman RA, Mason BE, Pelsang DJ, Sherman RM. Maggot debridement therapy. An alternative treatment for nonhealing ulcers. J Am Podiatr Med Assoc. 1995;85:218-221.

55. Sherman RA, Tran JM, Sullivan R. Maggot therapy for venous stasis ulcers. Arch Dermatol. 1996;132:254-256.

56. Bunkis J, Gherini S, Walton RL. Maggot therapy revisited. West J Med. 1985;142:554-556.

57. Horn KL, Cobb AH Jr, Gates GA. Maggot therapy for subacute mastoiditis. Arch Otolaryngol. 1976;102:377-379.

58. Borst GM, Goettler CE, Kachare SD, Sherman RA. Maggot therapy for elephantiasis nostras verrucosa reveals new applications and new complications: a case report. Int J Low Extrem Wounds. 2014;13:135-139.

59. Zarchi K, Jemec GB. The efficacy of maggot debridement therapy - a review of comparative clinical trials. Int Wound J. 2012;9:469-477.

60. Wilasrusmee C, Marjareonrungrung M, Eamkong S, et al. Maggot therapy for chronic ulcer: a retrospective cohort and a meta-analysis. Asian J Surg. 2014;37:138-147.

61. Tian X, Liang XM, Song GM, Zhao Y, Yang XL. Maggot debridement therapy for the treatment of diabetic foot ulcers: a meta-analysis. J Wound Care. 2013;22:462-469.

62. Sun X, Jiang K, Chen J, et al. A systematic review of maggot debridement therapy for chronically infected wounds and ulcers. Int J Infect Dis. 2014;25:32-37.

63. Dente K. Alternative treatments for wounds: leeches, maggots, and bees. Medscape. November 7, 2007. Available from: http:// http://www. medscape.com/viewarticle/563656. Accessed April 18, 2017. 
64. Evans J, Harris C, Jenkins M, et al. The all Wales guidance for the use of larval debridement therapy (ldt): All Wales Tissue Viability Nurse Forum and Biomonde; 2017, London.

65. Steenvoorde P, Oskam J. Bleeding complications in patients treated with maggot debridement therapy. Int J Low Extrem Wounds. 2005;4:57-58.

66. Herrett E, Thomas SL, Schoonen WM, Smeeth L, Hall AJ. Validation and validity of diagnoses in the General Practice Research Database: a systematic review. Br J Clin Pharmacol. 2010;69:4-14.

67. Cardiff University. HealthWise Wales. Available from: http://www. cardiff.ac.uk/centre-for-trials-research/research/studies-and-trials/view/ healthwise-wales. Accessed April 18, 2017.

68. Blueman D, Bousfield C. The use of larval therapy to reduce the bacterial load in chronic wounds. J Wound Care. 2012;21:244-253.

69. Cazander G, van Veen KE, Bernards AT, Jukema GN. Do maggots have an influence on bacterial growth? A study on the susceptibility of strains of six different bacterial species to maggots of Lucilia sericata and their excretions/secretions. J Tissue Viability. 2009;18:80-87.
70. Mumcuoglu KY, Miller J, Mumcuoglu M, Friger M, Tarshis M. Destruction of bacteria in the digestive tract of the maggot of Lucilia sericata (Diptera: Calliphoridae). J Med Entomol. 2001;38:161-166.

71. Nigam Y, Bexfield A, Thomas S, Ratcliffe NA. Maggot therapy: the science and implication for CAM part ii - maggots combat infection. Evid Based Complement Alternat Med. 2006;3:303-308.

72. Evans R, Dudley E, Nigam Y. Detection and partial characterization of antifungal bioactivity from the secretions of the medicinal maggot, Lucilia sericata. Wound Repair Regen. 2015;23:361-368.

73. Cazander G, Schreurs MW, Renwarin L, Dorresteijn C, Hamann D, Jukema GN. Maggot excretions affect the human complement system. Wound Repair Regen. 2012;20:879-886.

74. Linger RJ, Belikoff EJ, Yan Y, et al. Towards next generation maggot debridement therapy: transgenic Lucilia sericata larvae that produce and secrete a human growth factor. BMC Biotechnol. 2016;16:30.
Chronic Wound Care Management and Research

\section{Publish your work in this journal}

Chronic Wound Care Management and Research is an international, peer reviewed, open access, online journal publishing original research, reviews, editorials, and commentaries on the causes and management of chronic wounds and the major issues related to chronic wound management. Topics also include chronic wounds as comorbidities to other

\section{Dovepress}

conditions, patient adherence to therapy, and the economic burden of chronic wounds. The manuscript management system is completely online and includes a very quick and fair peer review system, which is all easy to use. Visit http://www.dovepress.com/testimonials.php to read real quotes from published authors.

Submit your manuscript here: https://www.dovepress.com/chronic-wound-care-management-and-research-journal 